\title{
Princípios para a curadoria técnica do acervo entomológico do Museu de Zoologia da Universidade de São Paulo
}

Fundamental principles of the curatorial work at the entomological collection of the Museum of Zoology of the University of Sao Paulo

1. Graduado em ciências biológicas pelo Instituto de Biociências da Universidade de São Paulo (IB-USP), mestre e doutor em ciências biológicas (zoologia) pelo IB-USP. Professor titular e curador da coleção de insetos Hymenoptera do Museu de Zoologia da USP. Diretor do MZ (2001-2005), vice-diretor do IEA (2014-2015), Presidente do IBRAM (20152016), Diretor do MAC USP (2016-2020) e Diretor-Presidente da Edusp (atual). E-mail:<crfbrand@usp.br>.

2. Graduada em ciências biológicas pela Pontifícia Universidade Católica do Rio Grande do Sul, mestra e doutora em ciências biológicas (entomologia) pela Universidade Federal do Paraná. Atualmente é pós-doutoranda no Museu de Zoologia da USP. E-mail: <kellisramos@gmail.com>.

3. Doutora pelo Programa de Pós-Graduação em Sistemática, Taxonomia Animal e Biodiversidade do Museu de Zoologia da USP. Mestre em zoologia pelo Programa de Pós-Graduação em Zoologia da Universidade Estadual de Feira de Santana. 
Bacharela e licenciada em ciências biológicas pela Universidade Federal de Santa Catarina. Atualmente é pós-doutoranda no Museu de Zoologia da USP. E-mail: <monicaulyssea@gmail. com>.

4. Graduado em ciências biológicas pela Universidade Presbiteriana Mackenzie, mestre em sistemática, taxonomia animal e biodiversidade pelo Museu de Zoologia da USP. Atualmente é doutorando do Programa Pós-Graduação em Sistemática, Taxonomia Animal e Biodiversidade pelo Museu de Zoologia da USP. E-mail: $<$ alvarods3@gmail.com>.

5. Graduada em ciências biológicas pelo Centro Universitário das Faculdades Metropolitanas Unidas. Realizou projetos de Iniciação Científica com bolsa do Programa de Capacitação em Taxonomia (Protax-CNPq) no Laboratório de Sistemática, Evolução e Biologia de Hymenoptera do Museu de Zoologia da USP. Mestre, com bolsa da Coordenação de Aperfeiçoamento de Pessoal de Nível Superior, junto ao Programa de Pós-Graduação em Sistemática, Taxonomia Animal e Biodiversidade do Museu de Zoologia da USP. E-mail: <tamiresandrade@usp.br>.
RESUMO: Este artigo trata das práticas curatoriais adotadas na seção de entomologia do Museu de Zoologia da Universidade de São Paulo. Adicionalmente, apresenta uma breve introdução sobre sua origem, a formação dos museus de história natural, os paradigmas adotados pela curadoria desde a formação do acervo, bem como os desafios para manter e disponibilizar as coleções no cenário atual de carência de técnicos e pesquisadores, inadequação de infraestrutura, diminuição do investimento em ciência e tecnologia e crescente aporte de material biológico para instituições oficiais feito por fontes externas ao museu.

PALAVRAS-CHAVE: Coleções biológicas. Preservação. Insetos.

ABSTRACT: This article discusses the curatorial practices adopted in the Entomology section of the Museum of Zoology of the University of Sao Paulo (MZ-USP). Moreover, it presents a brief introduction on the formation of Natural History Museums and the origins of the MZ-USP, exploring the paradigms adopted by the curatorship since the collection creation and the challenges in maintaining and making collections available in the current scenario of scarcity of technicians and researchers, inadequate infrastructure, decreased investment in Science and Technology, and increasing supply of biological samples from outside sources to official institutions.

KEYWORDS: Biological collections. Preservation. Insects. 
Coleções de história natural, ditas biológicas, têm como principal função armazenar e preservar espécimes que representem a diversidade dos organismos, tanto fósseis como atuais, fornecendo assim elementos para estudos taxonômicos, sistemáticos, ecológicos e biogeográficos. Entretanto, em razão da riqueza de leituras que permitem, são também fonte de informações históricas sobre o conhecimento acerca da biodiversidade e sobre os pesquisadores que a estudaram e estudam. Tais coleções detêm ainda informações fundamentais para que os países possam cumprir os compromissos e tratados internacionais dos quais são signatários.

Os antecessores das coleções científicas atuais foram os "gabinetes de curiosidades" (Kunstkammern ou Wunderkammern, gabinetes de cultura ou de maravilhas, em alemão), reunidos por nobres no Renascimento europeu e que acumulavam exemplares trazidos das explorações ou objetos curiosos ou raros. ${ }^{6}$ Um dos primeiros e mais famosos foi coligido pelo dinamarquês Ole Worm (15881654), contando com centenas de objetos de história natural cuidadosamente arranjados em uma sala de sua residência, catalogados por ele mesmo e publicado postumamente em 1655 sob o título de Museum Wormianum.?

gabinete de curiosidades do rico antiquário Elias Ashmole (1617-1692), de Oxford, Inglaterra, deu origem ao primeiro museu universitário (The Ashmolean Museum), em 1683, da Universidade de Oxford. ${ }^{8}$ Ashmole havia adquirido sua coleção de John Tradescant (1 608-1662) e de seu filho homônimo que, empregados pelo Conde de Salisbury, viajaram extensivamente pelo mundo conhecido de então, reunindo plantas exóticas para os jardins do conde e uma impressionante coleção de "curiosidades" que incluía espécimes zoológicos e botânicos, além de materiais geológicos. Os Tradescants haviam estabelecido um museu em 1634 em Lambeth, ao sul de Londres, conhecido como A Arca, contendo ainda o manto de Pocahontas e os restos taxidermizados da última ave dodô, jamais vista na Europa. Atualmente o Ashmolean Museum reúne departamentos de arte ocidental e oriental, de antiguidades, uma galeria de moldes e outra de numismática. ${ }^{9}$

As práticas de conservação de material biológico vêm se desenvolvendo desde os primórdios dos museus de história natural, há mais de dois séculos. Trata-se de um conhecimento prático que vem se acumulando e sendo compartilhado entre esses museus, de forma que é difícil traçar detalhes de sua história e os passos de sua disseminação. $\bigcirc$ intercâmbio constante de exemplares e de pessoal científico permitiu que a evolução das técnicas e métodos associados ao processo curatorial nos museus fosse compartida, de modo que se adota na maioria dos museus e
7. Cf. Romero-Reverón e Arráez-Aybar (2015).

8. Cf. Veiga (2015).

9. Funk (2018) apresenta uma revisão de como o campo científico mundial avançou a partir da crescente disponibilidade de dados provenientes de coleções biológicas do século XVIII ao XIX. 
10. Cf. Considera (2011) e Almeida (2018).

11. Cf. Kury, Giupponi e Mendes (2018).

12. Cf. Absolon, Figueiredo e Gallo (2018)

13. Cf. Santos (2000).

14. Cf. Costa (2013).

15. Cf. Simões (1981), Crispino, Bastos e Toledo (2006) e Sanjad et al. (2012).

16. Uma história dessas coleções iniciadas no século XIX e uma discussão crítica sobre as bases científicas e as táticas de pesquisa adotadas pelas instituições que as abrigam podem ser encontradas em Lopes (1992). coleções um conjunto semelhante de procedimentos técnicos, num paradigma que permite estudos comparativos e a soma de informações geograficamente dispersas, mas metodologicamente consistentes.

As coleções de pesquisa são abrigadas em universidades, institutos de pesquisa e museus, que contam com o espaço necessário para acondicionar o acervo. Coleçães de pesquisa podem ter caráter regional, reunindo espécimes de determinada localidade ou região geográfica, sendo fontes de consulta fundamentais por frequentemente conterem espécies endêmicas, além de serem importantes fontes de informação distribucional. Existem ainda coleções que privilegiam grupos de interesse para um determinado campo, como insetos de interesse para a veterinária e insetos pragas ou insetos coletados em levantamentos faunísticos. Acervos específicos podem ter personalidade própria ou integrar coleções maiores. Em alguns casos, coleções de pesquisa segregam coleções de tipos (espécimes que serviram de base às descrições de táxons), de maneira que em geral os tipos primários são mantidos à parte como forma de aumentar sua segurança.

As atividades de curadoria incluem a coleta, preservação, catalogação do material científico, decisões para o bom manejo das coleções, avaliação das necessidades e condições de empréstimo do material, doações e permutas, e toda a política prática e científica de como lidar com coleções. A curadoria dos acervos, em muitos casos, depende do empenho de professores ou pesquisadores, pósdoutores, de servidores técnicos, da colaboração de estagiários, pós-graduandos e de outras pessoas sem vínculo formal, já que nas instituições brasileiras não existem cargos específicos de curadores, quer científicos, quer técnicos.

No Brasil, a história desses acervos se iniciou com a fundação do Museu Real em 1818 por Dom João VI, ${ }^{10}$ depois chamado de Museu Nacional (da Quinta da Boa Vista) da Universidade Federal do Rio de Janeiro, que teve cerca de 80\% de suas coleções recentemente destruídas por um incêndio." $\bigcirc$ Museu Real ocupara um edifício no Campo de Santana e recebeu acervo antes abrigado na Casa de História Natural, popularmente chamada de Casa dos Pássaros, criada em 1784 pelo vice-rei Dom Luís de Vasconcelos e Sousa (1742-1809), que reunia coleções de mineralogia e zoologia. ${ }^{12}$ Com o exílio da família imperial em 1889, as coleções do Museu Nacional foram transferidas para o Paço de São Cristóvão. ${ }^{13}$ O Museu Paraense Emílio Goeldi, por sua vez, foi fundado em 1866, em Belém, capital do Pará, contando com acervos nas áreas de ciências naturais e humanas relacionados à Amazônia. ${ }^{14} \mathrm{~A}$ instituição promove pesquisas e estudos científicos dos sistemas naturais e culturais da região. ${ }^{15}$ É a mais antiga instituição na região amazônica e é reconhecida mundialmente como uma das mais importantes instituições de investigação científica sobre a Amazônia. ${ }^{16}$ 
Muitas outras coleções, em especial em universidades, surgiram no Brasil ao longo do século XX, compondo um capital estratégico para o país que permite definir suas políticas ambientais e que serve como base da formação de pessoal especializado, capaz de reconhecer e avaliar os cerca de $20 \%$ da biodiversidade do planeta que aqui se concentram. ${ }^{17}$

\section{O MUSEU DE ZOOLOGIA DA UNIVERSIDADE DE SÃO PAULO}

governo do estado de São Paulo organizou uma Comissão Geográfica e Geológica (CCG, 1886-1931) patrocinada pela elite cafeeira, que via em seus trabalhos a possibilidade de aumentar a produção do estado, bem como sua influência política. Os relatos, levantamentos cartográficos e estudos detalhados de geografia, geologia, climatologia, botânica, hidrografia e zoologia realizados pela CGG resultaram em farto material, reunido com a coleção particular do coronel Joaquim Sertório, que abrigava espécimes zoológicos, numismática, objetos históricos e curiosos, e a Coleção Peçanha (da qual pouco se conhece), em 1890, tornando-se o núcleo inicial do acervo do Museu Paulista, fundado em 1893. ${ }^{18}$

Inicialmente o Museu Paulista assumiu perfil enciclopédico, especialmente voltado à história natural. Nas duas décadas seguintes (de 1894 a 1916) constituiu considerável acervo de arqueologia e zoologia enquanto foi dirigido pelo zoólogo alemão Hermann von thering (1850-1930). No início do século XX, contava com as seções de história nacional, zoologia e botânica. ${ }^{19}$ A seção de zoologia do museu foi transferida para a Secretaria de Estado da Agricultura em 1939, como Departamento de Zoologia, que por sua vez foi incorporado à Universidade de São Paulo (USP) em 1969, recebendo finalmente a denominação de Museu de Zoologia. ${ }^{20}$ Atualmente o Museu de Zoologia abriga estimados 12 milhões de exemplares animais de todas as regiões do globo, em especial da região Neotropical e do Brasil. ${ }^{21}$

A partir de 1941 o Museu de Zoologia passou a ocupar edifício próprio, planejado por Cristiano Stockler das Neves (1889-1982), sendo a primeira edificação da cidade planejada para receber um museu, por um arquiteto que chegou a ser prefeito da cidade durante alguns meses, em 1947, e que fundou a Faculdade de Arquitetura e Urbanismo da Universidade Presbiteriana Mackenzie de São Paulo, a mais antiga da cidade. Essa ocupação praticamente coincidiu com uma mudança de paradigma na taxonomia zoológica. $\bigcirc$ sueco Carl Nilsson Linnaeus (1707-1778) criou o sistema de classificação hierárquica atualmente utilizado (com modificações) de forma universal pelos zoólogos. Nessa fase, consolidaram-se os
17. Cf. Granato (2019).

18. Cf. Brandão e Samara (2005).

19. Ibid., 2005.

20. Cf. Klingenberg e Brandão (2005) e Brandão e Costa (2007).

21. Cf. Museu de Zoologia da Universidade de São Paulo (2019). 
22. Cf. Wilkins (2009).

23. Mayr (1941).

24. Hennig (1966) procedimentos taxonômicos, isto é, de reconhecimento das espécies e de sua descrição, a partir das várias versões dos códigos internacionais de nomenclatura, paulatinamente aperfeiçoadas. Além de um conjunto de normas universais do código, os casos complexos são esclarecidos por uma comissão internacional.

Na acepção conhecida hoje como "tipológica", o exemplar tipo da espécie incorporaria todas as suas qualidades, no sentido aristotélico do termo, e deveria ser preservado em coleção perene de acesso público a pesquisadores, sendo todas as variações, porventura, registradas como desprezíveis, visto serem insuficientes para reconhecer um conjunto com identidade entre as variantes. Os museus de história natural dedicavam então espaço limitado para suas coleções, pois um exemplar de cada espécie, ou um número restrito, seria suficiente para uma boa preservação dos atributos das espécies. Tal noção já estava fragilizada em razão da enorme diversidade que se somou à conhecida até então pelas descobertas do Novo Mundo e das faunas tropicais, muitíssimas vezes mais ricas e diversas que as da Europa. Além disso, com a aceitação da teoria evolutiva no início do século XIX, a importância que as variações adquiriram como fonte das novidades evolutivas tornou fundamental não só reconhecer, mas também documentar.

Os avanços da genética abriram caminho para as investigações das razões subjacentes à variação intraespecífica, potencializadas pela genética de populações. Esse novo paradigma ${ }^{22}$ é reconhecido como a síntese evolutiva moderna, sistematizada por Ernst Mayr (1904-2005) em 1941,23 que inverteu essa lógica, tratando a variação como verdadeira e o tipo como falso. Nenhum exemplar, por mais "perfeito" que seja, representa mais ou melhor uma espécie do que qualquer outro, de maneira que é fundamental manter nos museus representantes dessas variações no tempo e no espaço, já que elas sim representam fielmente uma espécie. As coleções, para dar conta desse novo conceito de espécie, agora dito biológico e não mais tipológico, invadiram todos os espaços, laboratórios e corredores, exigindo, muitas vezes, a construção de mezaninos e o reforço das estruturas prediais. $\bigcirc$ edifício projetado do Museu de Zoologia incorpora acepç̃oes que, quando de sua ocupação, eram totalmente distintas das originais, se não contrárias; tudo isso em um intervalo de poucos anos e com efeitos sentidos na ocupação dos espaços até hoje.

Em seguida, a partir do fim dos anos 1950, com a publicação do livro de Willi Hennig 24 (Phylogenetic Systematics, na tradução do original em alemão) em 1966, houve uma profunda mudança nas teorias de classificação, com impactos nas coleções que passaram a se preocupar também com a guarda dos "semaforontes", isto é, dos diferentes estágios da vida de um organismo, que no todo comporiam o "holomorfo", o conjunto de todas as características morfológicas, 
fisiológicas, bioquímicas, comportamentais e ecológicas de um indivíduo. Mais recentemente as informações morfológicas passaram a ser organizadas e arquivadas na forma de matrizes de informações morfológicas, por meio de ferramentas cooperativas digitais como o Morphobank, ${ }^{25}$ que somente adiciona e disponibiliza informações verificadas por pares.

Com o emprego crescente de ferramentas moleculares a partir dos anos 1980, houve também a necessidade de manter amostras conservadas para viabilizar as investigações, em formato de bancos de tecidos e de depositários de informação genética como o Genbank. ${ }^{26}$

Por fim, a partir da Eco 92 no Rio de Janeiro e da adoção da Convenção sobre a Diversidade Biológica, passou-se a reconhecer o valor direto e indireto dos recursos ambientais, visando a distribuição equitativa dos benefícios advindos do uso econômico dos recursos genéticos, respeitada a soberania de cada nação sobre o patrimônio natural de seu território, dos proprietários da terra e dos detentores dos conhecimentos tradicionais. Para isso foi criado um mecanismo de depósito judicial de amostras da biodiversidade, que conta com museus e coleções oficiais como depositários oficiais, apesar de, muitas vezes, não serem assegurados os custos associados a esse incremento dos acervos.

O Museu de Zoologia da Universidade de São Paulo (MZ-USP) destaca-se, em escala mundial, pelo volume de suas coleções e pela qualidade da curadoria realizada ao longo de sua história de 120 anos, além das atividades de pesquisa, divulgação e formação de recursos humanos especializados em grau de excelência. A atual constituição do acervo é produto da aquisição de importantes coleções de especialistas, permutas com outras instituições, doações e coletas realizadas por meio de expedições organizadas pela própria instituição ou por outras instituições que têm o MZ-USP como repositório de amostras.

As espécies de insetos (Arthropoda: Hexapoda) representam mais da metade dos seres vivos macroscópicos, cerca de $70 \%$ dos animais, $73 \%$ dos invertebrados e $83 \%$ dos artrópodes do planeta. Ocupam praticamente todos os ambientes, tendo os mais diversos hábitos e funções; os papéis que desempenham nos diversos ecossistemas, mormente na polinização, ciclagem de nutrientes, herbivoria e controle das populações de outros organismos é inegável, corroborando a relevância dos acervos entomológicos. Os dados contidos nessas coleções, quando organizados, fornecem informações em vários planos, tais como padrões de distribuição, ciclos biológicos, controle de pragas e mudanças ambientais. Vale lembrar que os insetos são tão abundantes que as coletas para fins de documentação científica dificilmente causam algum impacto no tamanho de suas populações.
25. Cf. O'Leary e Kaufman (2011).

26. Cf. Benson et al. (2000). 
27. Cf. Museu de Zoologia da Universidade de São Paulo, op. cit.
As coleções entomológicas podem ser de diferentes tipos, de acordo com finalidades distintas (didáticas, particulares ou de pesquisa). As coleções didáticas são destinadas ao ensino e a treinamentos. Em razão do manuseio constante por um público pouco treinado, devem ser completamente independentes das coleções de pesquisa. Particulares reúnem e mantêm coleções privadas, e geralmente privilegiam grupos específicos, podendo ter grande valor para complementar o acervo das coleções públicas.

acervo do MZ-USP reúne cerca de 8 milhões de exemplares de insetos, ${ }^{27}$ com ênfase em coleópteros (besouros), dípteros (moscas e mosquitos), himenópteros (abelhas, vespas e formigas), lepidópteros (borboletas e mariposas) e cupins, mas inclui também valiosas coleções de muitas outras ordens de insetos, com exceção daquelas muito raras e que não ocorrem em território americano. Além disso, abriga milhares de espécimes-tipos que embasam a descrição das espécies. $\bigcirc$ acervo compreende atualmente uma das maiores coleções entomológicas públicas da América Latina, que salvaguarda uma diversidade extraordinária de espécimes de diferentes países, especialmente do Brasil.

A coleção entomológica hoje abrigada no Museu de Zoologia começou a ser formada ainda no Museu Paulista, a partir do intercâmbio de material com museus europeus, segundo orientação e contatos de Hermann von Ihering, reunindo exemplares representativos das famílias de insetos, o que permitiu identificar por comparação a fauna brasileira e descrever muitas espécies por meio de especialistas contatados no exterior. A esse núcleo inicial somou-se rapidamente o acervo de origem local coletado pelos especialistas do museu, com destaque para Hermann Luederwaldt ( 1 865-1934) e, por poucos anos, Curt Schrottky (1874-1937). Nas décadas de 1920 a 1940 José Pinto da Fonseca (1 896-1982) enriqueceu as coleções de insetos de interesse agrícola; a seguir, Lindolpho Rocha Guimarães (1908-1998) organizou importante coleção de insetos ectoparasitas, publicando trabalhos seminais e de importância internacional sobre as relações de parasitismo entre insetos e vertebrados. As coleções de besouros do MZ-USP receberam aportes importantes de Frederico Lane (1901-1991), Hans Reichardt (1937-1976), padre Francisco Pereira (1913-1991), Ubirajara Ribeiro Martins de Souza (1932-2015) e, atualmente, de Cleide Costa e Sônia Casari. $\bigcirc$ MZ-USP abriga uma importante coleção de Isoptera (cupins) organizada inicialmente por Renato L. Araújo (1912-1978), e atualmente por Eliana M. Cancello. As coleções de Hymenoptera se iniciaram com lhering, Luederwaldt e Schrottky e, recentemente, foram organizadas por Karol Lenko (1914-1975) e Carlos Roberto F. Brandão e seus alunos e colaboradores. Destacam-se ainda as coleções de dípteros - organizadas por Messias Carreira (1907-1994), José Henrique Guimarães (1937-2008), Maria Aparecida Vulcano (1921-2018) e, mais recentemente, por Nelson Papavero e 
Francisca C. do Val, com curadoria atual de Carlos Lamas - e a coleção de Lepidoptera, reunida por Lauro Pereira Travassos Filho (1918-1989) e atualmente sob responsabilidade de Marcelo Duarte. Deve-se pontuar também a contribuição de muitos colaboradores voluntários, técnicos com distintas formações e níveis de especialização e inúmeros alunos e estagiários que cooperaram na construção e guarda desse importante acervo, fonte fundamental para pesquisadores e estudantes de muitas procedências que visitam o MZ-USP ou que solicitam exemplares por empréstimo.

\section{PROCEDIMENTOS PRÁTICOS DE CURADORIA DOS ACERVOS ENTOMOLÓGICOS}

Descreveremos as práticas correntes adotadas pelo MZ-USP, em especial no que tange às coleções entomológicas, que estão em consonância com as técnicas empregadas na maioria de museus dessa tipologia, adaptadas às condições locais. ${ }^{28}$ Além disso, apresentaremos brevemente os condicionantes legais a que os acervos biológicos estão sujeitos, tanto para sua coleta como para a preservação e intercâmbio com o exterior.

Coleções biológicas podem abrigar espécimes coletados em ambientes naturais, urbanos ou associados a culturas agrícolas, além de poderem incluir ovos, imaturos, imagos, partes e produtos animais, como ninhos, pegadas e impressões fósseis. A formação de uma coleção biológica envolve a coleta, transporte, montagem, documentação, identificação, incorporação e manutenção do material, segundo uma metodologia racional definida e atendendo a um programa de pesquisa. Além disso, toda a atividade de curadoria de um acervo deve estar em conformidade com a legislação vigente sobre a biodiversidade do país, cabendo ao curador manter regularizados os trâmites relativos ao acesso do material da coleção para estudantes e pesquisadores, especialmente do exterior.

O Brasil é signatário da Convenção sobre o Comércio Internacional das Espécies da Flora e da Fauna Selvagem em Perigo de Extinção e, atendendo a resolução da convenção, dispõe de um cadastro Nacional de Coleções Biológicas, cujo objetivo é registrar as instituições científicas e regulamentar o transporte e intercâmbio de material biológico entre coleções. $\bigcirc$ cadastro registra as pessoas físicas e jurídicas detentoras de coleções, tendo sido instituído por meio de normativa do Instituto Brasileiro do Meio Ambiente e dos Recursos Naturais Renováveis (lbama). A legislação sobre a biodiversidade brasileira, Lei $13.123,{ }^{29}$ em vigor desde 17 de novembro de 2015, regula e cadastra no Sistema Nacional de Gestão do Patrimônio Genético e do Conhecimento Tradicional Associado 
(SisGen), sob controle do Conselho de Gestão do Patrimônio Genético (CGen), o acesso ao material biológico e ao conhecimento tradicional a ele associado. $\bigcirc$ CGen é um órgão do Ministério do Meio Ambiente de caráter deliberativo e normativo, criado com o intuito de regulamentar a utilização dos recursos genéticos nacionais. $\bigcirc$ envio e a remessa de amostras ou espécimes que contenham patrimônio genético brasileiro para o exterior, com a finalidade de acesso ao conhecimento ou para prestar serviço como parte de pesquisa ou desenvolvimento tecnológico, devem ser registrados no SisGen.

A coleta e o transporte de material biológico, por sua vez, são regulados por legislação que não pode ser ignorada por estudantes, professores e pesquisadores; é necessário obter licenças apropriadas junto aos órgãos ambientais competentes. O Ibama instituiu em 2007 o Sistema de Autorização e Informação em Biodiversidade (SISBio), cujo objetivo é fixar as normas para a concessão dessas autorizações e licenças. Após a criação do Instituto Chico Mendes de Conservação de Biodiversidade, o SISBio foi reestruturado e, desde 2014, está sob a gerência desse instituto.

Um cuidado básico com coleções de história natural de qualquer natureza é o controle das condições de iluminação. A luz natural altera a cor dos exemplares e deve ser controlada de forma permanente. Especialmente em regiões tropicais e subtropicais, os principais cuidados gerais para conservar os acervos biológicos estão centrados na proteção dos materiais em relação à umidade excessiva e ao combate a pragas, entre as quais os principais insetos-praga são, sobretudo, das famílias de besouros Anobiidae e Dermestidae (Coleoptera), além de insetos Psocoptera e Blattaria (baratas). Materiais biológicos guardados em caráter permanente eventualmente sofrem infestações causadas por fungos, cujos efeitos podem ser mitigados pela manutenção de condições climáticas adequadas (temperatura em torno de $22{ }^{\circ} \mathrm{C}$ e umidade relativa do ar entre 50 e 60\%). Sobretudo em instituições que não contam com climatização, o exame contínuo da coleção ainda é a forma mais eficaz de detectar problemas. Quanto antes eles forem resolvidos, maiores são as chances de serem combatidos e menores as possibilidades de transmissão para as áreas dos acervos ainda não afetadas.

exame constante da coleção permite verificar sinais iniciais de infestação e adotar medidas imediatas de segregação e tratamento do material infestado, evitando sua proliferação. Em geral, recomenda-se que todo material seja mantido em baixa temperatura em freezer por cerca de dez dias para expurgo antes de entrar no acervo. Recentemente, para todos os acervos de que se pretende obter amostras para trabalhos de biologia molecular, adotou-se a prática de conservação em álcool absoluto, permanentemente em freezer à temperatura de $-4{ }^{\circ} \mathrm{C}$. 
Todos os procedimentos de guarda permanente de quaisquer coleções biológicas devem ser acompanhados de medidas adequadas de documentação, de forma que a informação associada aos espécimes não se perca ou se empobreça ao longo do tempo.

\section{COLEÇÕES ENTOMOLÓGICAS}

Os cuidados ainda durante as atividades de coleta e as condições de guarda permanente das coleções, além das orientações dos curadores ou responsáveis, devem guiar as técnicas de preparação, montagem e conservação do material entomológico. O sucesso na captura de insetos de grupos taxonômicos de interesse depende de fatores como as condições climáticas, época do ano, fases lunares, metodologia de amostragem, escolha adequada do tipo de armadilha e experiência do coletor. De forma geral, as técnicas de coleta podem ser divididas em ativas - quando o coletor utiliza redes, aspiradores, guarda-chuva entomológico, panos de batida, panos brancos, pinças - ou passivas - quando a coleta depende indiretamente do coletor e a captura dos insetos é feita com auxílio de armadilhas, como a armadilha Malaise, armadilha luminosa, funil de Berlese-Tüllgren, isca atrativa, submissão de porções de serapilheira ao extrator de Winkler, armadilha de queda e pratos armadilhas (pan traps).

Nem sempre é possível preparar os insetos de imediato após a coleta. Para que sejam conservados, podem ser mantidos dentro de recipientes rígidos, hermeticamente fechados com um chumaço de algodão embebido em acetato de etila. Caso o intervalo entre a captura e sua montagem seja superior a dois dias, é recomendável mantê-los em congelador ou freezer. Insetos também podem ser conservados em álcool, ou outros líquidos apropriados, por vários anos antes de serem alfinetados. Para alguns grupos, no entanto, como mosquitos Culicidae, borboletas e mariposas, não é recomendada a preservação em meio líquido, por serem frágeis e apresentarem cerdas e escamas que são danificadas nesse tipo de conservação. Outra opção amplamente utilizada é a preservação a seco, que permite o armazenamento nas coleções por meio de mantas de algodão e envelopes de papel. Em qualquer dos meios de conservação temporária de insetos, os espécimes devem estar sempre acompanhados de etiquetas, cujos dados serão repassados para as etiquetas permanentes após a montagem do inseto e, em algumas instituições, para catálogos e/ou bancos de dados. 
Se os espécimes chegarem a enrijecer, é necessário relaxá-los antes de passar à montagem. Para isso, devem ser mantidos de 24 a 48 horas em câmara úmida - um recipiente de vidro ou plástico, hermeticamente fechado, no qual o fundo é preenchido por papel (ou tecido) encharcado em água ou por areia úmida com um pouco de algum inibidor do crescimento de fungos. Os insetos não devem ser colocados em contato direto com a água, mas protegidos em recipientes abertos (tais como placas de Petri).

É importante considerar que o tratamento de cada grupo de inseto exige procedimentos próprios, tanto para sua coleta e preparação quanto para seu armazenamento. Para a maioria dos grupos montados a seco são utilizados alfinetes de aço inoxidável de boa qualidade, principalmente em regiões tropicais com clima mais úmido. Alguns fatores devem ser observados no processo de montagem: (1) exposição de estruturas importantes para a identificação; (2) redução do risco de os espécimes serem danificados durante o manuseio; e (3) economia de espaço nas coleções. Além disso, para insetos muito pequenos, a montagem pode ser feita por meio da técnica de dupla montagem, com microalfinetes sobrepostos a um suporte de polietileno ou cortiça, que é montado em um alfinete entomológico. Em outra forma de dupla montagem, os exemplares são colados com cola branca escolar em triângulos de papel cartão de $\mathrm{PH}$ neutro, por sua vez alfinetados. Deve-se ter cuidado para permitir que os alfinetes sejam manipulados sem que os triângulos ou os exemplares sejam tocados, evitando contato com a mão, de maneira a preservar sua integridade. Os exemplares já em montagem definitiva devem ser mantidos em estufa a aproximadamente $40^{\circ} \mathrm{C}$ de 24 a 48 horas. Isso permite que os tecidos do corpo sequem conveniente e uniformemente, evitando que os insetos mofem. Por outro lado, a permanência na estufa por tempo prolongado (vários dias) torna os espécimes ressecados e excessivamente quebradiços.

Os alfinetes com os espécimes são mantidos em caixas de papelão com fundo de isopor, forradas com papel branco e guardadas em gavetas entomológicas de madeira em armários de aço, preferencialmente do tipo arquivos deslizantes, de forma a economizar e utilizar melhor o espaço. Em algumas coleções é empregada naftalina ou outro produto químico no interior das gavetas, impedindo ou retardando a infestação por outros organismos. $\bigcirc$ fundo de isopor, além de ser inerte e manter os alfinetes seguros em pé, revela rapidamente qualquer início de infestação do material por pragas, evidenciada pelo pó resultante da infestação sobre o fundo branco do isopor. Em geral, essas caixas de papelão são dimensionadas de forma a preencher totalmente o espaço interno das gavetas, evitando que, ao serem deslocadas, as caixas de papelão 
fiquem soltas dentro das gavetas, o que geraria risco de acidentes aos exemplares; assim, o tamanho dessas caixas deve ser adequado ao tamanho dos espécimes da coleção em questão. As gavetas de madeira precisam ser confeccionadas com madeira de boa qualidade para não se tornarem passíveis de infestação por cupins. Ademais, devem ter tampas de vidro, hermeticamente fechadas, para permitir o primeiro exame do conteúdo sem a necessidade de retirar a tampa. A disposição de gavetas nos armários de aço obedece, em geral, à classificação adotada pelo curador e/ou à ordem alfabética dos táxons, sempre de forma a possibilitar o acesso mais rápido e eficiente ao material procurado.

Pulgões, colêmbolos, proturos, dipluros, zorápteros, pulgas, piolhos e tisanópteros são montados sobre lâminas e cobertos por lamínulas em meios conservantes tradicionais, como xilol, bálsamo do Canadá, hidróxido de potássio, álcoois, fenol e creosoto, entre outros, todos apresentando maior ou menor risco à saúde humana. Essa técnica é especialmente recomendada para preparações definitivas de cochonilhas e os procedimentos podem envolver técnicas especiais de fixação e coloração.

Alguns grupos de insetos são mantidos em álcool 70 ou $80 \%$ (forma chamada de via úmida) em caráter permanente, sendo conservados em flaconetes, fechados com batoque e tampa de rosquear, preservados em potes plásticos sem álcool. Essa forma de manutenção é especialmente adequada para insetos que sofrem dessecação, como cupins.

Insetos que se fixam em galhos e folhas são mantidos secos em tubos de vidro de tamanho adequado, guardados em gavetas entomológicas.

Tanto os insetos mantidos em via seca quanto úmida são guardados em armários de aço; as gavetas que abrigam as coleções em via úmida também devem ser de aço para minimizar possíveis infestações.

\section{DESAFIOS ATUAIS PARA AS COLEÇÕES BIOLÓGICAS}

Um dos principais reptos está relacionado aos altos custos de infraestrutura e manutenção dos acervos, assim como à carência de recursos humanos especializados. No Brasil, grande parte das coleç̃ões entomológicas foi formada e é mantida por meio do esforço isolado de pesquisadores e de suas respectivas instituições, que recebem apoios financeiros pontuais, visto que não há no país uma política de longo prazo de fomento com esse objetivo. ${ }^{30} \mathrm{Com}$ a adoção de 
31. Cf. Short, Dikow e Moreau (2018).

32. Cf. Zaher e Young, op. cit., Short, Dikow e Moreau, op. cit.

33. Cf. Santos et al. (2002).

34. Cf. Funk, op. cit.

35. Cf. Buckup (2014)

36. Cf. Kury et al. (2006). conceitos modernos de espécie e o novo papel que as coleções científicas assumiram, as coleções seriadas de espécimes de insetos multiplicaram-se em tamanho, gerando desafios estruturais quanto aos espaços necessários para abrigálas. Numa medida para otimizar os espaços, por exemplo, progressivamente vêm sendo adotados arquivos deslizantes compactadores, adequados para a guarda de muitos indivíduos, com as adaptações necessárias para cada tipologia de acervo, o que pode gerar sobrecarga na estrutura de edifícios muitas vezes não programados para esse fim. Além disso, em relação à economia de espaço ocupado por coleções de insetos, especialmente no caso de espécies sociais, espécimes réplicas podem ser conservados em meio líquido em lotes.

Tradicionalmente, busca-se preservar no acervo entomológico a morfologia externa dos indivíduos. No entanto, novas tecnologias vêm sendo cada vez mais empregadas, entre elas o exame em microscópio eletrônico de varredura, em microscópio confocal e as imagens de radiografia e tomografia, o que tem permitido ampliar em muito o número e a natureza dos caracteres cujo estudo serve de base ao exame das questões sobre as quais os museus se debruçam. ${ }^{31}$ Além destas, os dados moleculares vêm se tornando imprescindíveis nos estudos em vários campos do conhecimento e as coleções passaram a representar bancos genéticos de amostras de tecidos. ${ }^{32} \mathrm{~A}$ implantação e a manutenção de bancos de tecidos visam preservar genomas para a extração de DNA, além de fazerem parte dos compromissos dos países que seguem as premissas da Convenção em Diversidade Biológica. ${ }^{33}$ Além disso, as coleções são importantes na conservação dos exemplares cujas sequências moleculares foram extraídas para garantir a possibilidade de checar a identidade do espécime ou para quaisquer novas consultas ao material-testemunho que sejam necessárias. ${ }^{34} \mathrm{~A}$ grande disseminação de técnicas moleculares no estudo da biodiversidade de insetos tem modificado a forma como os espécimes são coligidos, preservados e catalogados. Essas novas demandas envolvem a elaboração de novas metodologias de custódia de material biológico, associadas à manutenção do material testemunho (vouchers), coleções de tecidos e extratos de DNA, ${ }^{35}$ assim como infraestrutura e insumos específicos para essa finalidade.

Com o advento de novas tecnologias de informática, o aprimoramento de computadores de mesa e redes de internet, o compartilhamento de informações digitalizadas de espécimes biológicos depositados em coleções científicas vem facilitando os processos de curadoria e pesquisa de dados, assim como a divulgação do acervo institucional. ${ }^{36} \mathrm{~A}$ criação e a disponibilidade pública de bases de dados dos espécimes depositados em coleções tornam-nas paulatinamente uma ferramenta extremamente importante na exploração de dados para pesquisas direcionadas principalmente ao estudo da biodiversidade e à 
conservação em escala local e global. A aplicação dessas informações pode ajudar a compreender quais partes do mundo são prioritárias para a amostragem da fauna de insetos, quantas e quais espécies são raras em acervos e merecem atenção especial, quais táxons não foram coletados nas últimas décadas e podem estar extintos, quais áreas ou ecossistemas apresentam alto índice de endemismo e estão sob risco de degradação, quão rápida uma espécie invasora ocupa e se adapta a uma nova área, e como a composição de uma comunidade de insetos mudou ao longo do tempo, entre outras questões. ${ }^{37}$

Por outro lado, o tamanho e a complexidade das coleções entomológicas torna desafiadora a tarefa de digitalizar as informações relativas aos espécimes, em comparação com outras coleções de história natural. ${ }^{38}$ Diversos são os desafios no processo de digitalizar um acervo entomológico, como a decisão de quais exemplares deverão ter seus dados informatizados, a obtenção de imagens /de espécimes ou gavetas entomológicas), a definição sobre que dados serão catalogados e disponibilizados, e a plataforma que será adotada para digitalizar e divulgar os dados. $\bigcirc$ Brasil conta com algumas plataformas on-line que integram dados sobre a biodiversidade de insetos em coleções, provenientes de fontes diversas do Brasil e do exterior. Uma das principais iniciativas é o Sistema de Informação sobre a Biodiversidade Brasileira, que o MZ-USP integra e na qual vem trabalhando para digitalizar seu acervo. No momento, o financiamento para digitalizar a coleção entomológica foi descontinuado e apenas uma parcela do acervo está disponível para consulta pública.

Outra questão importante e relativamente recente é a adequação dos procedimentos curatoriais às novas normas e regulamentações brasileira, como a Lei 13.123, de 2015,39 que trata da conservação da diversidade biológica, da utilização sustentável de seus componentes e da repartição justa e equitativa dos benefícios derivados do uso de seus recursos genéticos. ${ }^{40}$ As exigências das principais entidades federais relacionadas às atividades inerentes à rotina de coleções biológicas ainda suscitam dificuldades para a interpretação e cumprimento dessas diretrizes. Por exemplo, algumas disposições da Resolução CGen n 12 , de $2018,{ }^{41}$ sobre a remessa de material para outros países, exigiram a reformulação das cláusulas do Termo de Transferência de Material e da Guia de Remessa. Essas alterações suscitaram dúvidas, especialmente em pesquisadores e instituições do exterior, que não se sentiram confortáveis em assumir as responsabilidades imputadas pelas leis brasileiras sem as conhecer integralmente. ${ }^{42}$

Em relação à coleta de espécimes, o SISBio estabelece que: "sempre que houver a coleta de material biológico, é indispensável que haja uma instituição brasileira responsável e devidamente capacitada para receber o
37. Cf. Funk, op. cit.

38. Cf. Short, Dikow e Moreau, op. cit.

39. Brasil, op. cit.

40. Cf. Santos et al. (2018).

41. Brasil (2018).

42. Cf. Santos et al., op. cit. 
43. Cf. Zaher e Young, op. cit. e Santos et al., op. cit.

44. Cf. Santos et al., op. cit. 45. Cf. Zaher e Young, op. cit., Kury et al. (2006). material em depósito. $\bigcirc$ depósito de material biológico coletado deverá ser feito em coleção biológica científica". Isso gera um problema de ordem prática, uma vez que o SISBio não determina, por exemplo, se as instituições detentoras de coleções científicas deverão salvaguardar todo o material coligido ou apenas uma amostra dele. Alguns estudos, como os de impacto ambiental realizados por empresas de consultoria, resultam na coleta de muitos exemplares, geralmente das espécies mais comuns, que ocupam recursos e espaços já escassos em instituições que mantêm coleções relativamente grandes. As coleções nacionais enfrentam enormes dificuldades para manter seus acervos em condições adequadas, por falta de recursos financeiros e humanos, infraestrutura e insumos básicos para sua manutenção. ${ }^{43}$ Portanto, é fundamental uma política de fomento direcionada às coleções que atendem aos propósitos das agências de controle ambiental por determinação legal. ${ }^{44}$

Essas questões discutidas influenciam forte e diretamente diferentes aspectos da atividade de curadoria, não somente da coleção entomológica do MZ-USP, mas também de outros acervos da instituição e de outras coleções brasileiras. A incorporação de novas metodologias relativas ao gerenciamento dos acervos facilita o processamento dos espécimes e a disponibilidade das informações que thes são associadas. $\bigcirc$ Brasil, como signatário da Convenção sobre Diversidade Biológica, precisa adotar medidas complementares às estratégias de conservação, medidas que envolvam a manutenção de componentes da diversidade biológica fora de seus hábitats naturais, isło é, em coleções biológicas (chamadas de condições ex situ). Entretanto, a maioria dos acervos brasileiros carece de infraestrutura compatível com as necessidades de armazenamento, preparação, segurança e estudo do material científico. Além disso, urge ao país elaborar uma política de financiamento a longo prazo que invista na capacidade de suporte e infraestrutura dos acervos, na contratação de profissionais qualificados e na manutenção de suas coleções. Atualmente, reconhece-se que os recursos biológicos são propriedades estratégicas do país que os detém e que são imprescindíveis para o desenvolvimento científico e tecnológico de uma nação. As coleções representam o conhecimento acumulado sobre a biodiversidade passada e presente, fornecendo informações valiosas para as decisões sobre políticas públicas e projeções de cenários, além de constituírem uma fonte inesgotável de informação essencial, que permite realizar descobertas importantes ainda fora do alcance tecnológico dessa geração. ${ }^{45}$ 


\section{Agradecimentos}

Este trabalho foi realizado com o apoio da Fundação de Amparo à Pesquisa do Estado de São Paulo (Fapesp) (processos 17/07366-1 e 2016/50378-8) e pelo Programa de Capacitação em Taxonomia (Protax) do Conselho Nacional de Desenvolvimento Científico e Tecnológico (CNPq) (processo 440574/201 15-3). Mônica Antunes Ulysséa agradece à Fapesp pela bolsa de pós-doutorado (processo 2018 / 1 1453-0|; Alvaro Doria dos Santos à Coordenação de Aperfeiçoamento de Pessoal de Nível Superior (Capes) pela bolsa de doutorado (código de financiamento 88887.302820/2018-00); e Tamires de Oliveira Andrade à Capes pela bolsa de mestrado (código de financiamento 001). Agradecemos a leitura crítica da professora Ana G. Magalhães. 


\section{REFERÊNCIAS}

FONTES IMPRESSAS

BRASIL. Lei $\mathrm{n}^{\circ}$ 13.123, de 20 de maio de 2015. Diário Oficial da União, Brasília, DF, 14 maio 2015. Disponível em: <https://bit.ly/2TSh1Su>. Acesso em: 9 jun. 2021.

BRASIL. Ministério do Meio Ambiente. Resolução CGen n ${ }^{\circ}$ 12, de 18 de setembro de 2018. Diário Oficial da União, Brasília, DF, 19 out. 2018. Disponível em: <https://bit.ly/3v5dn4n>. Acesso em: 9 jun. 2021.

LIVROS, ARTIGOS E TESES

ABSOlON, Bruno Araujo; FIGUEIREDO, Francisco José de; GAlLO, Valéria. O primeiro gabinete de história natural do Brasil ("Casa dos Pássaros") e a contribuição de Francisco Xavier Cardoso Caldeira. Filosofia e História da Biologia, São Paulo, v. 13, n. 1, p. 1-22, 2018.

ALMEIDA, Allison. Museu Nacional celebra 200 anos. Ciência e Cultura, São Paulo, v. 70, n. 3, p. 62-64, 2018. Doi: doi.org/10.21800/2317-66602018000300017.

ALMEIDA, Lúcia Massutti de; COSTA, Cibele S. Ribeiro; MARINONI, Luciane. Manual de coleta, conservação, montagem e identificação de insetos. Ribeirão Preto: Holos, 1998.

BENSON, Dennis et al. GenBank. Nucleic Acids Research, Oxford, v. 28, n. 1, p. 15-18, 2000. Doi: <https://doi.org/10.1093/nar/28.1.15>.

BRANDÃO, Carlos Roberto Ferreira; COSTA, Cleide. Uma crônica da integração dos museus estatutários à USP. Anais do Museu Paulista, São Paulo, v. 1, n. 1, p. 207-217, 2007. Doi: <https://doi.org/10.1590/S0101-47142007000100005>.

BRANDÃO, Carlos Roberto Ferreira; SAMARA, Eni de Mesquita. Da difusão à pesquisa no Estado de São Paulo: a história do Museu Paulista da Universidade de São Paulo. Revista de Cultura e Extensão da USP, São Paulo, n. 0, p. 94-103, 2005.

BUCKUP, Paulo Andreas. Coleções biológicas e coleções de DNA e sua aplicação ao estudo da biodiversidade. In: SIMPÓSIO SOBRE A BIODIVERSIDADE DA MATA ATLÂNTICA, 3., 2014, Santa Teresa. Anais [...]. Santa Teresa: Inma, 2014. p. 33-44.

CAMARgO, Amabílio José Aires et al. Coleções entomológicas: legislação brasileira, coleta, curadoria e taxonomia para as principais ordens. Brasília, DF: Embrapa, 2015. 
CONSIDERA, Andrea Fernandes. Museus de história natural no Brasil (1818-1932): uma revisão bibliográfica. In: SIMPÓSIO NACIONAL DE HISTÓRIA, 26., 2011, São Paulo. Anais [...]. São Paulo: Anpuh, 2011. p. 1-8.

COSTA, Rafaela Paiva. Carlos Estevão de Oliveira e o Museu Paraense Emílio Goeldi (19301945). In: JORNADA DE HISTÓRIA DA CIÊNCIA E ENSINO, 4., 2013, São Paulo. Anais [...]. Belém: Museu Goeldi, 2014. p. 39-59.

CRISPINO, Luis Carlos Bassalo; BASTOS, Vera Burlamaqui; TOLEDO, Peter Mann de. As origens do Museu Paraense Emílio Goeldi: aspectos históricos e iconográficos. Belém: Paka-Tatu, 2006.

FUNK, Vicki. Collections-based science in the 21st Century. Journal of Systematics and Evolution, Hoboken, v. 56, n. 3, p. 175-193, 2018. Doi: <https://doi.org/10.1111/jse.12315>.

GRANATO, Marcus et al. Lista dos museus universitários brasileiros. [S. l.: s. n.], 2019. Disponível em: <http://www.mast.br/images/projetos_de_pesquisa/2019/outubro/listagemmuseus-universitarios- 31-10-19.pdf>. Acesso em: 26 out. 2019.

HENNIG, Willi. Phylogenetic systematics. Urbana: University of Illinois Press, 1966.

KLINGENBERG, Christiana; BRANDÃO, Carlos Roberto. The type specimens of fungus growing ants, Attini (Hymenoptera, Formicidae, Myrmicinae) deposited in the Museu de Zoologia da Universidade de São Paulo, Brazil. Papéis Avulsos de Zoologia, São Paulo, v. 45, n. 4, p. 41-50, 2005. Doi: <https://doi.org/10.1590/S0031-10492005000400001>.

KURY, Adriano Brilhante; GIUPPONI, Alessandro Ponce de Leão; MENDES, Amanda. Immolation of Museu Nacional, Rio de Janeiro: unforgettable fire and irreplaceable loss. The Journal of Arachnology, Washington, DC, v. 46, n. 3, p. 556-558, 2018. Doi: <https://doi. org/10.1636/JoA-S-18-094.1>.

KURY, Adriano Brilhante et al. Diretrizes e estratégias para a modernização de coleções biológicas brasileiras e a consolidação de sistemas integrados de informação sobre biodiversidade. Brasília, DF: Ministério da Ciência e Tecnologia, 2006.

LOPES, Maria Margaret. O Brasil descobre a pesquisa científica: os museus de ciências naturais no século XIX. São Paulo: Hucitec, 1997.

MAYR, Ernst. Animal species and evolution. Cambridge: Harvard University Press, 1941.

MUSEU DE ZOOLOGIA DA UNIVERSIDADE DE SÃO PAULO. MZUSP Museu de Zoologia da Universidade de São Paulo. São Paulo: MZ-USP, 2019. Material institucional.

O'LEARY, Maureen; KAUFMAN, Seth. MorphoBank: phylophenomics in the "cloud". Cladistics, Hoboken, v. 27, n. 5, p. 529-537, 2011. Doi: <https://doi.org/10.1111/j.1096-0031.2011.00355.x>. 
RAFAEL, José Albertino et al. (eds.). Insetos do Brasil: diversidade e taxonomia. Ribeirão Preto: Holos, 2012.

RAFFAINI, Patrícia Tavares. Museu contemporâneo e os gabinetes de curiosidades. Revista do Museu de Arqueologia e Etnologia, São Paulo, n. 3, p. 159-164, 1993. Doi: <https://doi. org/10.11606/issn.2448-1750.revmae.1993.109170>.

ROMERO-REVERÓN, Rafael; ARRÁEZ-AYBAR, Luis. Ole Worm (1588-1654): anatomist and antiquarian. European Journal of Anatomy, Salamanca, v. 19, n. 3, p. 299-301, 2015.

SANJAD, Nelson et al. Documentos para a história do mais antigo jardim zoológico do Brasil: o Parque Zoobotânico do Museu Goeldi. Boletim do Museu Paraense Emílio Goeldi: Ciências Humanas, Belém, v. 7, n. 1, p. 197-258, 2012. Doi: <https://doi.org/10.1590/S1981$81222012000100013>$.

SANTOS, Hugo Ricardo Secioso et al. Os impactos da legislação ambiental brasileira sobre as coleções biológicas. Diversidade e Gestão, Rio de Janeiro, v. 2, n. 2, p. 52-61, 2018.

SANTOS, Myriam. Os museus brasileiros e a constituição do imaginário nacional. Sociedade e Estado, Brasília, DF, v. 15, n. 2, p. 271-302, 2000. Doi: <https://doi.org/10.1590/S010269922000000200005>.

SHORT, Andrew Edward; DIKOW, Torsten; MOREAU, Corrie. Entomological collections in the age of big data. Annual Review of Entomology, Palo Alto, v. 63, p. 513-530, 2018. Doi: <https:// doi.org/10.1146/annurev-ento-031616-035536>.

SIMÕES, Mario Ferreira. As pesquisas arqueológicas no Museu Paraense Emílio Goeldi (18701981). Acta Amazonica, Manaus, v. 11, n. 1, p. 149-165, 1981. Doi: <https://doi. org/10.1590/1809-43921981111s149>.

VEIGA, Verine Stochi. Elias Ashmole e suas contribuições para a divulgação da ciência durante o século XVII. 2015. Dissertação (Mestrado em História da Ciência) - Pontifícia Universidade Católica de São Paulo, São Paulo, 2015.

WILKINS, John. Species: a history of the idea. Berkeley: University of California Press, 2009.

ZAHER, Hussam; YOUNG, Paulo. As coleções zoológicas brasileiras: panorama e desafios. Ciência e Cultura, São Paulo, v. 55, n. 3, p. 24-26, 2003.

Artigo apresentado em: 15/04/2020. Aprovado em: 10/10/2020. (c) BY 